\title{
Response surface optimization of Rhodamine B dye removal using paper industry waste as adsorbent
}

\author{
Anita Thakur ${ }^{1} \cdot$ Harpreet Kaur ${ }^{1}$
}

Received: 10 December 2015/Accepted: 13 February 2017/Published online: 16 February 2017

(C) The Author(s) 2017. This article is published with open access at Springerlink.com

\begin{abstract}
The present investigation describes the conversion of waste product into effective adsorbent and its application for the treatment of wastewater, i.e., chemically modified solid waste from paper industry has been tested for its adsorption ability for the successful removal of Rhodamine B dye from its aqueous solution. The adsorption isotherm, kinetics and thermodynamic parameters of process have been determined by monitoring the different parameters, such as effect of $\mathrm{pH}$, amount of adsorbent dose, concentration, contact time and temperature. The equilibrium data has been well described on the basis of various adsorption isotherms, namely Langmuir, Freundlich and Temkin adsorption isotherm. From Langmuir isotherm, the maximum monolayer adsorption capacity has been found to be $6.711 \mathrm{mg} \mathrm{g}^{-1}$ at $308 \mathrm{~K}$ temperature. The kinetics of adsorption has been studied using pseudo-first order, pseudo-second order and intra-particle diffusion model and the results show that kinetics has been well described by pseudo-second order. Thermodynamic parameters, such as free energy change $(\Delta G)$, enthalpy change $(\Delta H)$ and entropy change $(\Delta S)$, have been evaluated. The free energy has been obtained as $-11.9452 \mathrm{~kJ} \mathrm{~mol}^{-1}$ for $75 \mathrm{mg} \mathrm{L}^{-1}$ concentration at $308 \mathrm{~K}$ temperature. Desorption and recycling efficiency of adsorbent has been studied and the adsorbent shows good recycling efficiency.
\end{abstract}

Keywords Paper industry waste $\cdot$ Rhodamine B . Adsorption · Kinetics · Isotherms

Harpreet Kaur

preetjudge@yahoo.co.in

1 Department of Chemistry, Punjabi University, Patiala 147002, India

\author{
Abbreviations \\ CMSW Chemically modified solid waste \\ BET Brunauer-Emmett-Teller \\ SEM Scanning electron microscope \\ FTIR Fourier transformation infrared spectroscopy \\ EDAX Energy dispersive X-ray spectroscopy

\section{List of symbols} \\ $q_{e} \quad$ Adsorption capacity \\ $C_{0} \quad$ Initial equilibrium concentration \\ $C_{\mathrm{e}} \quad$ Final equilibrium concentration \\ $V \quad$ Volume of the solution \\ $W \quad$ Weight of adsorbent \\ $q_{m} \quad$ Maximum adsorption capacity \\ $b_{L} \quad$ Energy of adsorption \\ $R_{L} \quad$ Dimensionless constant \\ $K_{f} \quad$ Freundlich constant \\ $1 / n \quad$ Heterogeneity factor \\ $R^{2} \quad$ Regression coefficient \\ $B$ Intensity of adsorption \\ $K_{T} \quad$ Constant related to adsorption capacity \\ $K_{2} \quad$ Pseudo-second order coefficient \\ $t \quad$ Time \\ $K_{\text {ipd }}$ Intra-particle diffusion rate constant \\ $\Delta S \quad$ Entropy change \\ $\Delta H \quad$ Enthalpy change \\ $\Delta G \quad$ Free energy change
}

\section{Introduction}

India ranks third among the leading textile-producing countries in the world behind China and European nations, and more than 95 million peoples got engaged in textile and related sectors in India [1]. But despites of 
significance, the textile industries are the main source of pollution due to discharge of hazardous effluent containing colours and organic chemicals used for bleaching, dyeing, printing and other finishing processes [2]. Globally, about $10-15 \%$ of total dyestuff (equivalent to 280,000 tonnes) is released annually into the environment during the manufacturing of textile products, which leads to the contamination of water reservoirs, and thereby affects human and animal health $[3,4]$.

One of the most commonly used dyes in industries is Rhodamine B dye. Rhodamine B is synthetically prepared xanthene cationic dye and widely used for paper printing and as a colourant in textile and food stuff [5]. It is harmful to both human beings and animals, because if this dye is swallowed it can cause irritation to skin, eyes and respiratory track [6]. It has been medically proven that drinking water contaminated with Rhodamine B dye is highly carcinogenic, neurotoxin and chronic [7, 8]. Thus, the wastewater contaminated with Rhodamine B dye must be treated carefully before discharged into water streams [9].

A number of conventional physical, chemical and biological methods, such as ion-exchange [10], coagulation/flocculation [11], reverse osmosis [12], membrane filtration [13], electrochemical oxidation [14], electrochemical degradation [15], photodegradation [16], and heterocatalytic Fenton oxidation [17], have been used for the removal of dyes. The serious drawbacks of these methods are low efficiency, disposal of waste, low sensitivity, etc. [18, 19]. Among all these, adsorption has been found to be very simple and innovative method for treating dye wastewater even at very low concentration of dyes [20]. In adsorption process, adsorbate adhered on the surface of adsorbent by physical, chemical or electrostatic forces [21]. Activated carbon has been the most widely used adsorbent for the wastewater treatment due to its high surface area and high adsorption capacity [22]. Though the removal of dyes through activated carbon is very effective, but sometimes its use is restricted due to its high cost and difficulties associated with regeneration [23]. The removal of hazardous dyes through adsorption technique using industrial waste materials, such as blast furnace dust, sludge, slag from steel plant and carbon slurry from fertilizer plant [24], chitosan [25], bottom ash [26], and agriculture wastes, such as date palm [27], coconut tree flowers [28] have been already reported.

The paper industries produce a large amount of sludge every year, which can be used as an adsorbent for the removal of dyes. Thus, this study aimed to investigate the potential use of CMSW for the removal of hazardous dye Rhodamine B.

\section{Experimental}

\section{Materials and methods}

\section{Preparation of dye solution}

Rhodamine is a basic dye having IUPAC name [9-(2-carboxyphenyl)-6-diethylamino-3-xanthenylidene]-diethylammonium chloride has been purchased from S.D. Fine chemicals, Mumbai, India. Stock solution of dye ( $500 \mathrm{mg} \mathrm{L}^{-1}$ ) has been prepared by dissolving $0.5 \mathrm{~g}$ of dye in $1000 \mathrm{~mL}$ of deionised water. Another solution of desired concentration has been prepared by successive dilutions of the stock solution. Concentration of the dye after adsorption has been determined using Shimadzu-1800 UV Visible Spectrophotometer at $553 \mathrm{~nm}$ wavelength.

\section{Preparation of adsorbent}

The waste material (sludge) from paper industry has been used as an adsorbent for the removal of dye. The sludge has been washed with deionised water and dried (under sunlight) and then kept in the oven at $100{ }^{\circ} \mathrm{C}$ for 3 days. The dried material has been grounded into fine powder. The finely powdered sludge has been mixed with sulphuric acid and kept overnight and then washed with deionised water to remove residue acid. The material has been dried at $100{ }^{\circ} \mathrm{C}$ for $24 \mathrm{~h}$ and then grounded, sieved and kept in air tight container for further uses.

\section{Adsorption studies}

Batch adsorption studies of removal of Rhodamine B dye onto CMSW has been carried out as a function of initial dye concentration, contact time, adsorbent dose and $\mathrm{pH}$. All the adsorption experiments have been conducted by shaking $100 \mathrm{~mL}$ of solution of definite concentration of dye along with fixed amount of adsorbent at room temperature $(308 \mathrm{~K})$ and $\mathrm{pH}(4.40)$ at constant speed on mechanical shaker. $5 \mathrm{~mL}$ of solution has been withdrawn at pre-determined time intervals. The concentration of Rhodamine B dye in solution has been determined using UVVisible spectrophotometer. During adsorption, equilibrium has been established between adsorbed dye on active sites of adsorbent and unadsorbed dye in the solution. The percentage of dye adsorbed and adsorption capacity at equilibrium has been calculated by the following formula:

Percentage adsorption $(\%)=\frac{\left(C_{0}-C_{\mathrm{e}}\right)}{C_{0}} \times 100$

$q_{\mathrm{e}}=\frac{\left(C_{0}-C_{\mathrm{e}}\right)}{W} V$ 
where $C_{0}$ and $C_{\mathrm{e}}$ represent the initial and final equilibrium concentrations $\left(\mathrm{mg} \mathrm{L}^{-1}\right), V$ is the volume of solution and $W$ is the weight of adsorbent.

\section{Effect of contact time}

The influence of contact time on the adsorption process has been studied for different intervals of time, i.e., 10, 20, 30, 45, 60, 90 and $120 \mathrm{~min}$. The initial dye concentration and adsorbent dose chosen for this study were $50 \mathrm{mg} \mathrm{L}^{-1}$ and $2.0 \mathrm{~g}$, respectively.

\section{Effect of initial dye concentration}

The effect of initial dye concentration $(25,50,75,100$ and $125 \mathrm{mg} \mathrm{L}^{-1}$ ) on percentage adsorption has been analysed by agitating $100 \mathrm{~mL}$ of dye solution along with $2.0 \mathrm{~g}$ of adsorbent for equilibrium time, i.e., $60 \mathrm{~min}$.

\section{Effect of adsorbent dose}

Variable amount of CMSW dose $(0.5,1.0,1.5,2.0$ and $2.5 \mathrm{~g}$ ) has been agitated along with $100 \mathrm{~mL}$ of dye solution $\left(50 \mathrm{mg} \mathrm{L}^{-1}\right)$ for different intervals of time as described above.

\section{Effect of $\mathrm{pH}$ and ionic strength}

To investigate the effect of solution $\mathrm{pH}$ on the colorant adsorption, the $\mathrm{pH}$ values of solutions has been adjusted to $\mathrm{pH} 2.40,4.40,8.40$ and 10.40 using $1 \mathrm{~N}$ sodium hydroxide and $1 \mathrm{~N}$ hydrochloric acid. The $\mathrm{pH}$ of solution has been monitored with the help of $\mathrm{pH}$-meter. The effect has been studied by stirring dye solution of concentration $50 \mathrm{mg} \mathrm{L}^{-1}$ along with adsorbent $(2.0 \mathrm{~g})$ for $60 \mathrm{~min}$.

\section{Effect of temperature}

To study the effect of temperature on the adsorption of Rhodamine B by CMSW, the experiments have been performed at three different temperatures, i.e., 308, 313 and $318 \mathrm{~K}$. The concentration of dye taken is $50 \mathrm{mg} \mathrm{L}^{-1}$ and CMSW dose is $2.0 \mathrm{~g}$.

\section{Effect of surfactant}

The effect of surfactant has been studied by agitating $100 \mathrm{~mL}$ of dye $(50 \mathrm{mg} / \mathrm{L})$ solution along with $10 \mathrm{mg}$ of sodium dodecyl sulphate and $2.0 \mathrm{~g}$ of CMSW.

\section{Desorption studies}

For the desorption studies, the adsorbent collected after adsorption has been dried and divided into three parts. One part is dissolved in water, other in $1 \mathrm{~N}$ acetic acid and remaining in $1 \mathrm{~N}$ hydrochloric acid for $24 \mathrm{~h}$ and then washed gently with water to remove any unadsorbed dye. To study the recycling efficiency, $2.0 \mathrm{~g}$ of adsorbent collected after desorption with water, acetic acid and hydrochloric acid has been agitated separately with $100 \mathrm{~mL}$ of dye solution of $50 \mathrm{mg} \mathrm{L}^{-1}$ concentration for $60 \mathrm{~min}$. The solutions after adsorption have been subjected to UV-Visible spectrophotometer to determine the amount of dye adsorbed.

\section{Characterization of adsorbent}

\section{BET, SEM, FT-IR and EDAX studies}

The physical parameters, such as surface area, total pore volume and mean pore diameter of CMSW has been determined using (Belstrop mini Japan) Brunauer, Emmett and Teller (BET) $\mathrm{N}_{2}$ sorption procedure with liquid $\mathrm{N}_{2}$ at $-195.72{ }^{\circ} \mathrm{C}$. For the BET analysis, the material has been degassed. The sample materials is placed in a vacuum chamber at a very low constant temperature $\left(-195.72{ }^{\circ} \mathrm{C}\right)$ and it is operated at a wide range of pressure. The surface area, mean pore volume and mean pore diameter of CMSW has been found as $1600 \mathrm{~cm}^{2} \mathrm{~g}^{-1}, 0.1083 \mathrm{~cm}^{3} \mathrm{~g}^{-1}$ and $27.058 \mathrm{~nm}$, respectively. As compared with the surface area of other adsorbents, such as bottom ash $\left(870.5 \mathrm{~cm}^{2} \mathrm{~g}^{-1}\right)$ and deoiled soya $\left(728.6 \mathrm{~cm}^{2} \mathrm{~g}^{-1}\right)$, CSMW shows a very good surface area [29].

Scanning electron microscopy has been used as a primary source for characterizing the surface morphology and fundamental physical properties of the adsorbent. Figure 1a indicates that before adsorption the surface is rough and porous, so there is a good possibility for the dye to be adsorbed into these pores. It is clear from Fig. $1 b$ that after adsorption the surface becomes smooth, which indicates that the surface of adsorbent is covered with dye molecules.

CMSW has been characterized using Fourier transformation infrared, i.e., FT-IR analysis. The FT-IR spectrum of CMSW before and after adsorption has been shown in Fig. 2, in which the lower one is unloaded CMSW and the upper one is loaded CMSW with Rhodamine B dye. The spectrum of unloaded CMSW shows weak absorption band at $3675 \mathrm{~cm}^{-1}$ corresponds to hydroxyl group $(-\mathrm{OH})$ stretching. An absorption band at $2915 \mathrm{~cm}^{-1}$ corresponding to $\mathrm{C}-\mathrm{H}$ stretching of the $\mathrm{CH}_{2}$ groups, which indicates the presence of various amino groups. The spectrum shows weak absorption band at $1620 \mathrm{~cm}^{-1}$, which may be due to $-\mathrm{C}=\mathrm{O}$ stretching. The peak around $1260 \mathrm{~cm}^{-1}$ may be due the presence of lignin [30].The weak absorption bands at 
Fig. 1 a Scanning electron micrographs (SEM) of CMSW before adsorption. b Scanning electron micrographs (SEM) of CMSW after adsorption
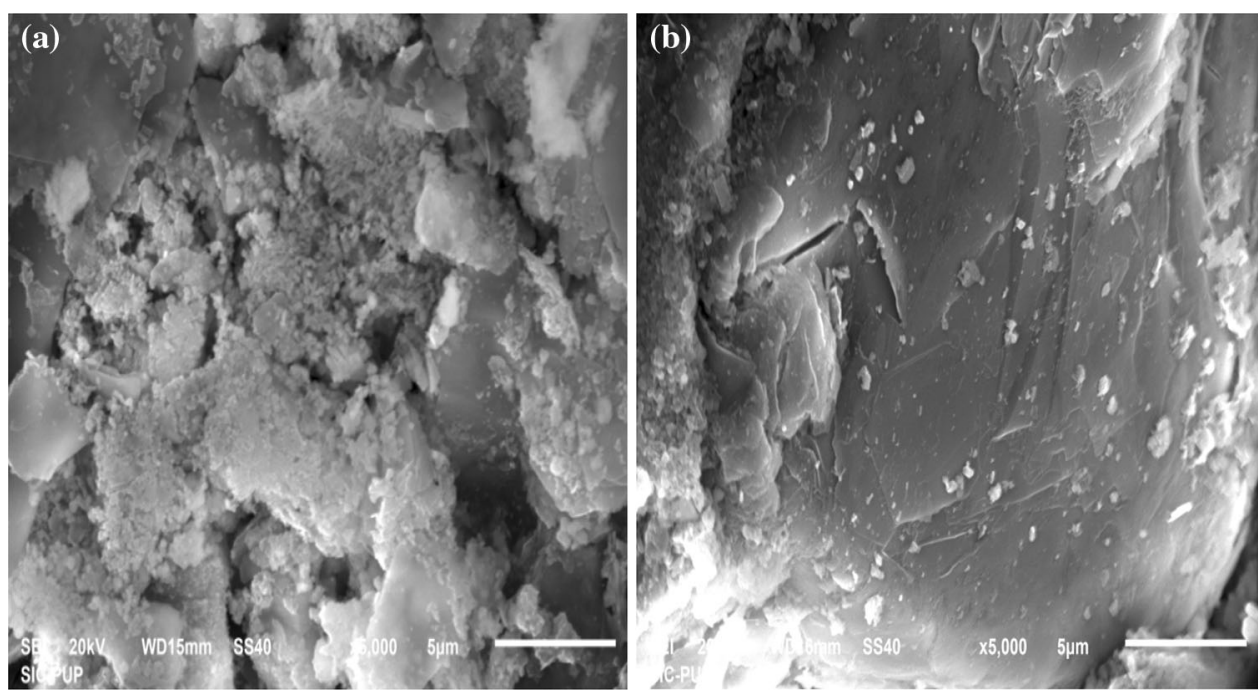

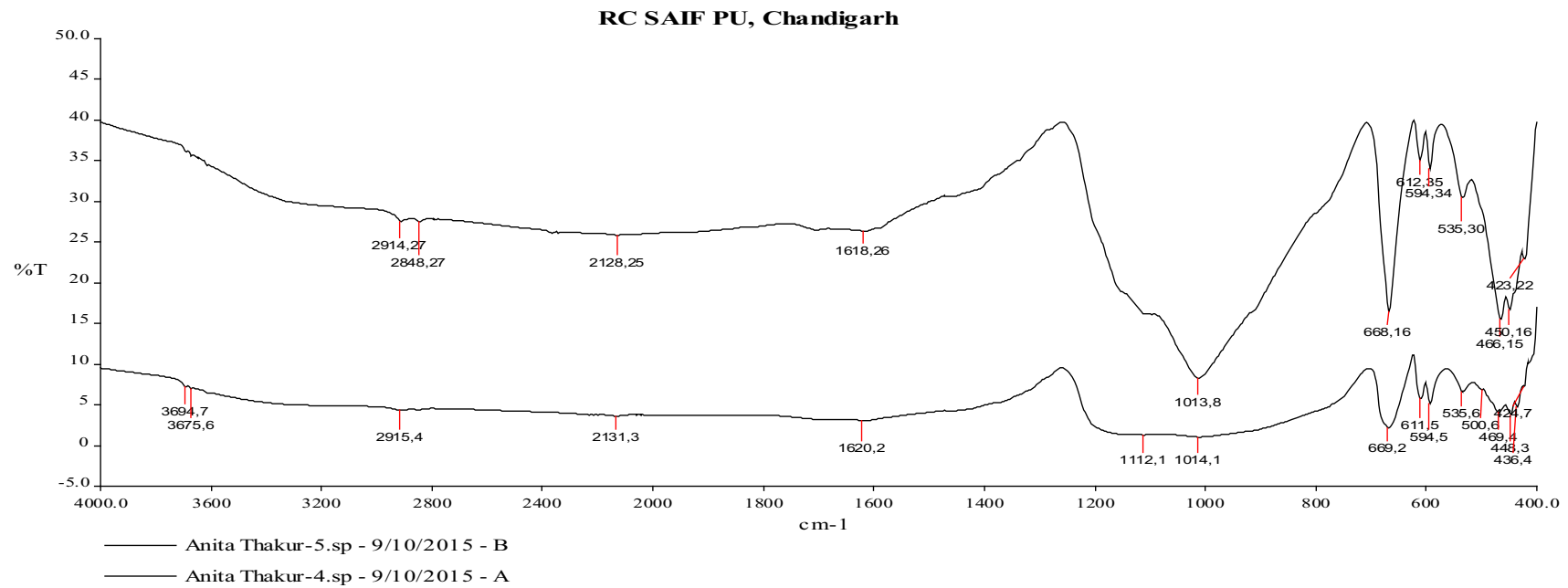

Fig. 2 FTIR spectra of loaded and unloaded CMSW

1121 and $1014 \mathrm{~cm}^{-1}$ may be attributed to $-\mathrm{C}=\mathrm{N}$ and $\mathrm{C}-\mathrm{O}$ stretching of polysaccharide like substances. The stretching vibration in the region $700-600 \mathrm{~cm}^{-1}$ may be assigned to $\mathrm{C}-\mathrm{S}$ linkage and peak due to brominated compounds may be appeared in the region of $600-500 \mathrm{~cm}^{-1}$. The absorption band due to $-\mathrm{OH}$ and $-\mathrm{C}=\mathrm{N}$ stretching is missing after adsorption, which shows that these may be involved in the adsorption process. There is slight shifting of peaks of adsorbent after adsorption. No new peak has been observed, which indicates that no chemical bond is formed between adsorbate and adsorbent after adsorption, i.e., FTIR data supports that adsorption of dye on adsorbent is due to physical forces.

The chemical composition of adsorbent has been determined using EDAX analysis. Figure 3 shows the elemental percentage composition of $\mathrm{O}, \mathrm{C}, \mathrm{Si}, \mathrm{S}, \mathrm{Mg}$ and $\mathrm{Al}$ in CMSW adsorbent. The oxygen content has been found to be maximum in CMSW, i.e., 51.26\%. The carbon content has been found to be $32.06 \%$. The other contents, such as silicon, sulphur, magnesium and aluminium have been found to be $6.86,4.61,4.48$ and $0.73 \%$, respectively. Higher oxygen contents indicate that metal ions must be present in oxide form.

\section{Results and discussion}

\section{A batch adsorption study}

\section{Effect of contact time}

The adsorption potential of CMSW towards Rhodamine B dye as a function of contact time has been shown in 
Fig. 3 EDAX spectra of CMSW

Fig. 4 a Effect of contact time and initial dye concentration on $\%$ removal of dye. Initial dye concentration $=50 \mathrm{mg} \mathrm{L}^{-1}$, contact time $=60 \mathrm{~min}$, adsorbent dose $=2.0 \mathrm{~g}$. b Effect of contact time and initial dye concentration on adsorption capacity of dye. Initial dye concentration $=50 \mathrm{mg} \mathrm{L}^{-1}$ contact time $=60 \mathrm{~min}$, adsorbent dose $=2.0 \mathrm{~g}$
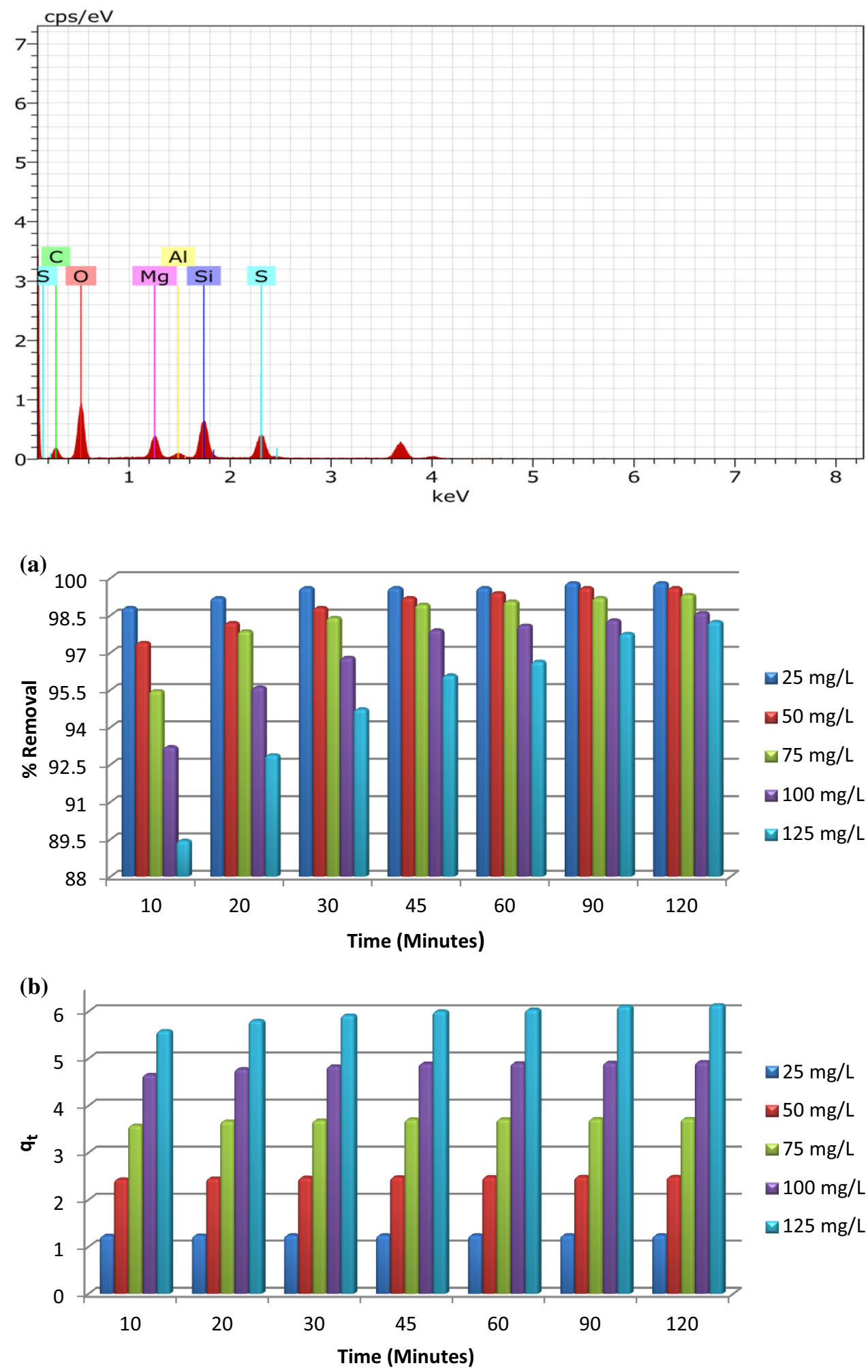

Fig. 4a, b and it is evident from figures that percentage removal of Rhodamine $\mathrm{B}$ dye has been increased with increase in contact time. The percentage removal has been found to be rapid in early stages of adsorption and remained almost constant after $60 \mathrm{~min}$. This is due to the reason that at initial stages, all the active sites are free for adsorption, but after $60 \mathrm{~min}$ equilibrium is established between dye in solution and dye on adsorbent, i.e., there is electrostatic hindrance or repulsion between the adsorbed dye onto the adsorbent surface $[6,31]$. Approximately 
Table 1 Contact time for Rhodamine B adsorption on various adsorbents

\begin{tabular}{lcc}
\hline Adsorbents & $\begin{array}{l}\text { Equilibrium contact } \\
\text { time (min) }\end{array}$ & References \\
\hline Walnut shell & 80 & {$[32]$} \\
Casuarina equisetifolia needles & 180 & {$[33]$} \\
Rise husk & 180 & {$[34]$} \\
Coconut shell activated carbon & 180 & {$[35]$} \\
TyphaAngustata L plant materials & 210 & {$[36]$} \\
Walnut shell charcoal & 300 & {$[37]$} \\
CMSW & 60 & Present \\
& & study \\
\hline
\end{tabular}

99\% of dye has been removed within 10 min at all initial concentrations, which shows that CMSW is a good adsorbent. A comparison of contact time for the adsorption of Rhodamine B dye onto CMSW with other adsorbents (Table 1) shows that CMSW takes lesser contact time for adsorption.

\section{Effect of initial dye concentration}

The data indicate that percentage of dye removed decreases with increase in the initial concentration of dye. As at lower concentration, maximum dye particles in solution occupy available binding sites on adsorbent, which results in better adsorption [38]. But at higher concentration, the available sites on the adsorbent become limited and there is no further adsorption. In case of adsorption capacity, the adsorption capacity increases with increase in initial dye concentration because the increase in initial dye concentration enhances the interaction between dye and adsorbent $[35,37,39]$.

\section{Effect of adsorbent dose}

In adsorption process, the amount of adsorbent dose is an important parameter because it determines the potential of adsorbent to remove the dye at a particular given concentration. It has been observed that percentage of dye removed increases from 79.20 to $99.80 \%$ and adsorption capacity decreases from 7.92 to $1.996 \mathrm{mg} \mathrm{g}^{-1}$ as amount of CMSW increased from 0.5 to $2.5 \mathrm{~g}$. The increase in percentage removal at higher adsorbent dose is attributed to the fact that by increasing the amount of adsorbent dose, the adsorptive surface area increases, due to which the number of available sites increases and results in increase in percentage removal [29, 32, 33]. But the adsorption capacity decreases with increase in adsorbent dose because there is a split in concentration gradient between the concentration of dye in solution and that on the surface of adsorbent [40] (Fig. 5). (a) - 60 minutes

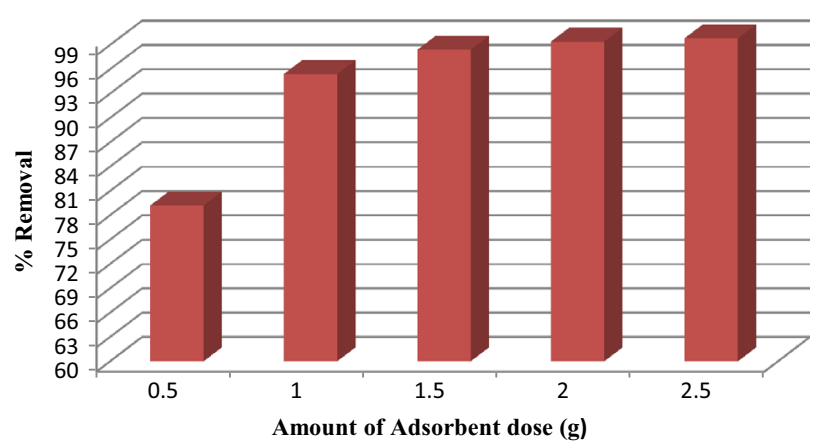

(b)

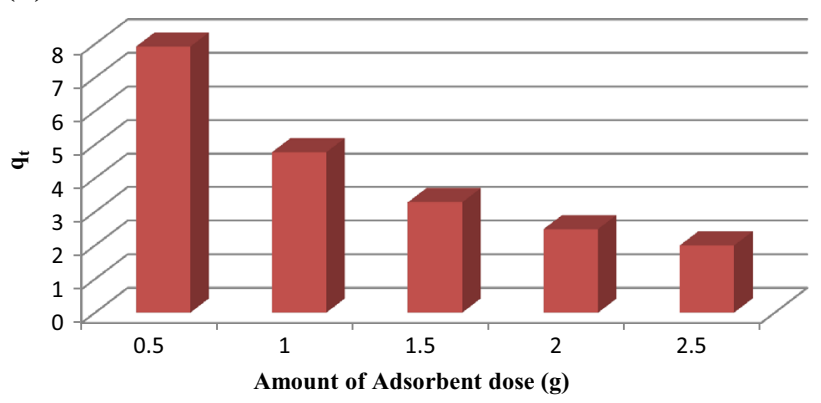

Fig. 5 a Effect of adsorbent dose on percentage removal of dye. Contact time $=60 \mathrm{~min}$. Initial dye concentration $=50 \mathrm{mg} \mathrm{L}^{-1}$. b Effect of adsorbent dose on adsorption capacity of dye. Initial dye concentration $=50 \mathrm{mg} \mathrm{L}^{-1}$, contact time $=60 \mathrm{~min}$

\section{Effect of $p H$ and ionic strength}

The $\mathrm{pH}$ of solution plays an important role in adsorption process because it directly affects the dissociative and adsorptive ability of dye on the surface of adsorbent [41]. Figure 6 shows that removal of dye is higher in acidic medium than alkaline medium. It may be explained on the bases that change in $\mathrm{pH}$ of the solution results in the formation of different ionic species and different carbon surface charges. When the $\mathrm{pH}$ is lower, the Rhodamine B dye exists in cationic and monomeric form and is able to easily enter in the pores of adsorbent. But as the $\mathrm{pH}$ increases, the zwitterionic form of Rhodamine B in water may lead to the aggregation of dye molecules to dimmers [42]. Due to large size at high $\mathrm{pH}$, dye molecules are enabling to fit, and this results in decrease in percentage removal at higher $\mathrm{pH}$.

The effect of ionic strength is also important because it verify the attraction between the non-polar groups of dye and adsorbent, i.e., hydrophobic-hydrophobic interactions. It has been observed that adsorption has been increased with increase in ionic strength, i.e., with the addition of $\mathrm{NaCl}\left(0.1 \mathrm{~mol} \mathrm{~L}^{-1} \mathrm{NaCl}\right)$. This may be due to the fact that with increase in ionic strength, there is a partial neutralization of the positive charge on the adsorbent surface. The high ionic strength enhances the hydrophobic-hydrophobic interactions by compression of electric double layer that 


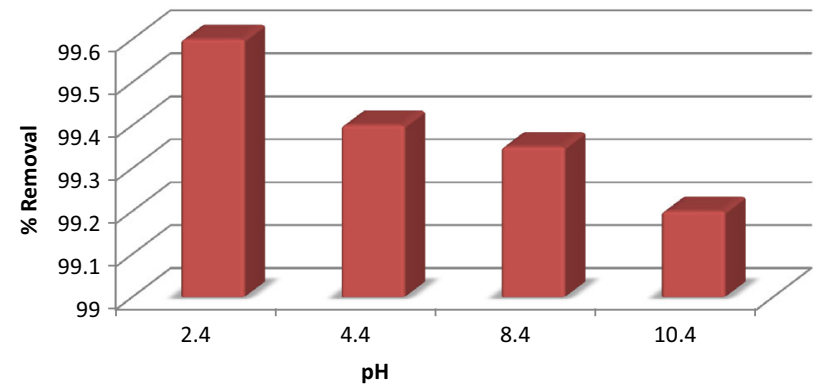

Fig. 6 Effect of $\mathrm{pH}$ on percentage removal of dye. Initial dye concentration $=50 \mathrm{mg} \mathrm{L}^{-1}$, contact time $=60 \mathrm{~min}$, adsorbent dose $=2.0 \mathrm{~g}$

moves particles much closer, which leads to increase in dye adsorption [43].

\section{Effect of temperature}

Since adsorption is a temperature dependent process. Thus, the removal of dye has been studied at three different temperatures, i.e., 308,313 and $318 \mathrm{~K}$. The extent of adsorption of dye has been found to be slightly increased with increase in temperature (Fig. 7), indicating the endothermic nature of the process [36, 44].

\section{Effect of surfactant}

The adsorption of cationic dye onto CMSW has been studied in the presence of anionic surfactant sodium dodecyl sulfate (SDS). The result indicates that $100 \%$ of dye has been removed using SDS along with the adsorbent. This can be explained on the fact that Rhodamine B is cationic dye and SDS is anionic surfactant, so there is more adsorption of ionic solute in the presence of oppositely charged surfactant, i.e., electrostatic attraction between adsorbate and adsorbent increases (Fig .8).

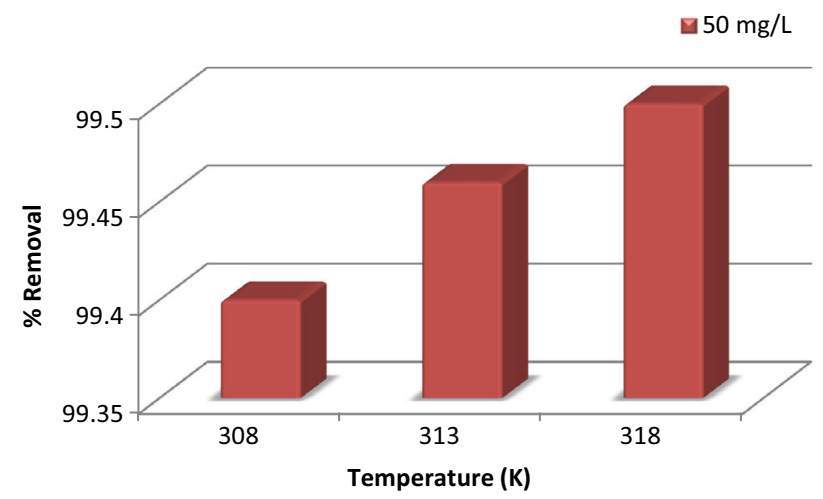

Fig. 7 Effect of temperature percentage removal of dye. Initial dye concentration $=50 \mathrm{mg} \mathrm{L}^{-1}, \quad$ contact time $=60 \mathrm{~min}$, adsorbent dose $=2.0 \mathrm{~g}$

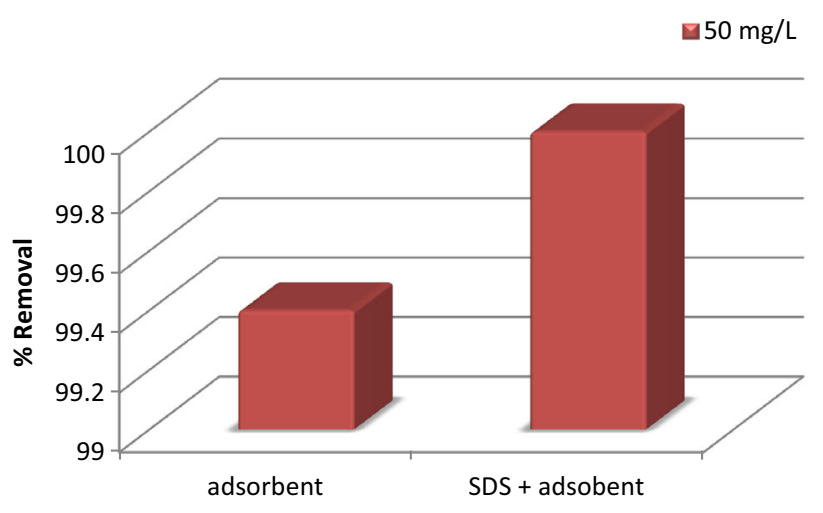

Fig. 8 Effect of surfactant on percentage removal of dye. Initial dye concentration $=50 \mathrm{mg} \mathrm{L}^{-1}$, contact time $=60 \mathrm{~min}$, adsorbent dose $=2.0 \mathrm{~g}$, SDS dose $=100 \mathrm{mg}$

\section{Desorption studies}

Desorption studies help to elucidate the nature of interaction existing between adsorbate and adsorbent and the recycling of adsorbent. It is evident from Fig. 9 that the adsorbent which is treated with hydrochloric acid desorbed to maximum extent, i.e., why a large amount of dye has been removed using hydrochloric acid treated desorbed adsorbent. It indicates that hydrochloric acid has good regenerating power and CMSW shows good recycling efficiency.

\section{Adsorption isotherms}

The data of adsorption studies has been tested with Langmuir, Freundlich and Temkin adsorption isotherms.

\section{Langmuir adsorption isotherm}

The isotherm is based on the assumption that the adsorption takes place at specific homogeneous sites on the adsorbent surface and is monolayer in nature.

The linear equation for Langmuir isotherm model is given below [45]:

$\frac{C_{\mathrm{e}}}{q_{e}}=\frac{C_{\mathrm{e}}}{q_{m}}+\frac{1}{q_{m} \cdot b_{L}}$

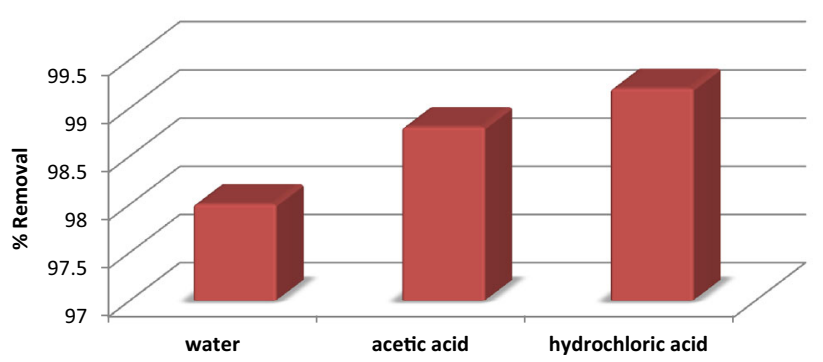

Fig. 9 Desorption studies using various solvents 
where, $q_{m}$ and $b_{L}$ are the Langmuir constants related to the maximum adsorption capacity $\left(\mathrm{mg} \mathrm{g}^{-1}\right)$ and energy of adsorption $\left(\mathrm{L} \mathrm{mg}^{-1}\right)$. The values of $q_{m}$ and $b_{L}$ have been determined from the slope and intercept of plot between $C_{\mathrm{e}} / q_{e}$ versus the $C_{\mathrm{e}}$ and are listed in Table 3 . The essential characteristics of Langmuir isotherm can be expressed by a dimensionless constant called equilibrium parameter $R_{L}$, which is defined by equation:

$R_{L}=\frac{1}{\left(1+b_{L} \cdot C_{0}\right)}$

The value of $R_{L}$ indicated the type of Langmuir isotherm to be irreversible $\left(R_{L}=0\right)$, favourable $\left(0<R_{L}<1\right)$, linear $\left(R_{L}=1\right)$, or unfavourable $\left(R_{L}>1\right)$. The $R_{L}$ was found to be $0.010,0.009$ and 0.007 for $50 \mathrm{mg} \mathrm{L}^{-1}$ concentration of Rhodamine B dye at 308,313 and $318 \mathrm{~K}$ temperatures, respectively, which indicates the favourable adsorption.

A comparison of adsorbent capacity of CMSW with other adsorbents (Table 2) shows that CMSW has a better adsorption capacity than others (Fig. 10).

\section{Freundlich adsorption isotherm}

Freundlich adsorption isotherm is an empirical adsorption isotherm describing the adsorption on heterogeneous surface. This isotherm does not predict any saturation of the adsorbent by the adsorbate, indicating multilayer adsorption.

Freundlich isotherm can be described by the equation given below [56]:

Table 2 Comparison of adsorption capacities of different waste adsorbents for Rhodamine B removal

\begin{tabular}{lll}
\hline Waste materials & $\begin{array}{l}\text { Adsorption } \\
\text { capacity } \\
\left(\mathrm{mg} \mathrm{g}^{-1}\right)\end{array}$ & References \\
\hline Fly ash & 2.330 & {$[46]$} \\
Iron chromium oxide (ICO) & 2.980 & {$[47]$} \\
Tamarind fruit shell Activated carbon & 3.940 & {$[48]$} \\
Coir pith & 2.560 & {$[49]$} \\
Raw orange peel & 3.230 & {$[50]$} \\
Natural diatomite & 8.130 & {$[51]$} \\
Mimusops Elengi activated carbon & 1.700 & {$[52]$} \\
Mango leaf powder & 3.310 & {$[30]$} \\
Pigeon dropping & 8.550 & {$[6]$} \\
Walnut shell & 1.541 & {$[32]$} \\
Coconut shell carbon & 2.330 & {$[35]$} \\
Akash Kinari coal & 1.183 & {$[53]$} \\
Mango leaf powder & 3.310 & $\underline{[54} \underline{]}$ \\
Raw Flint Clay & 1.488 & $\underline{[55]}$ \\
Exhausted coffee ground powder & 5.255 & {$[7]$} \\
Paper industry waste sludge & 6.711 & Present \\
& & study \\
\hline
\end{tabular}

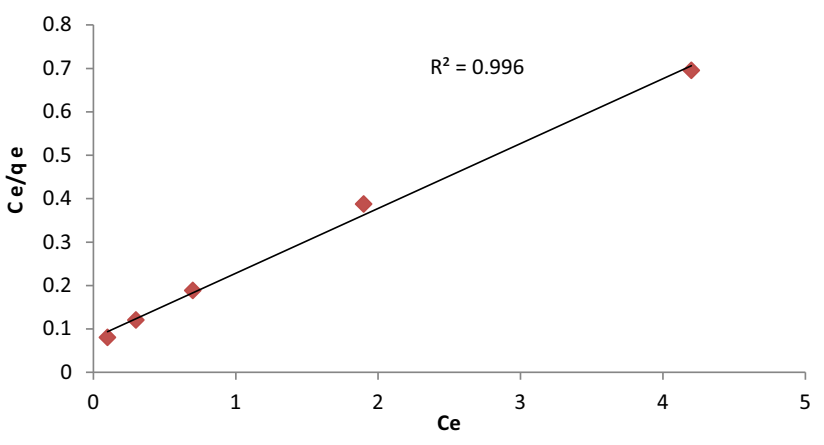

Fig. 10 Langmuir adsorption isotherm for Rhodamine B adsorption at $308 \mathrm{~K}$

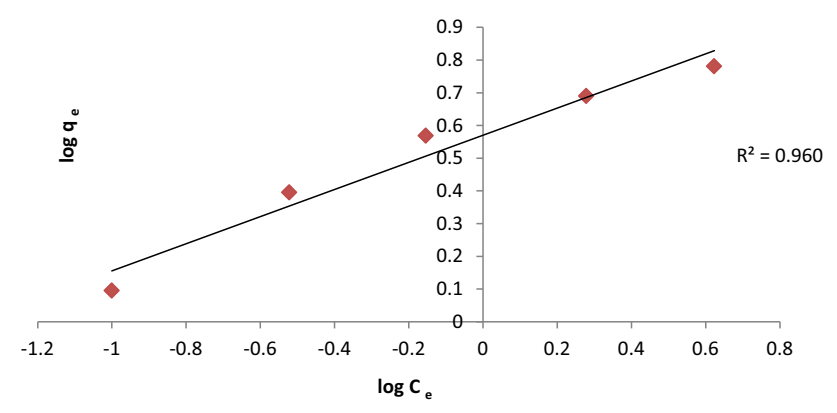

Fig. 11 Freundlich adsorption isotherm for Rhodamine B adsorption at $308 \mathrm{~K}$

$\log q_{e}=\log K_{f}+\frac{1}{n} \log C_{\mathrm{e}}$

where $K_{f}$ is Freundlich constant and $1 / n$ is the heterogeneity factor. It is evident from Fig. 11 that data fit well to Freundlich adsorption isotherm with regression coefficient $R^{2}=0.960$. The values of $K_{f}$ and $1 / n$ have been calculated from intercept and slope of this straight line (listed in Table 3).

\section{Temkin adsorption isotherm}

The linear form of Temkin isotherm model is given by the following equation (by Temkin and Pyzhev)

$q_{e}=B \ln K_{T}+B \ln C_{\mathrm{e}}$

where, $K_{T}$ and $B$ are the constants related to adsorption capacity and intensity of adsorption, respectively. A linear plot between $q_{e}$ verses $\ln C_{\mathrm{e}}$ shows that adsorption follows Temkin isotherm. The values of $K_{T}$ and $B$ have been evaluated from slope and intercept of the plot (Fig. 12).

\section{Adsorption kinetics}

The data of adsorption of Rhodamine $\mathrm{B}$ dye has been applied to pseudo-first order, pseudo-second order and intra-particle diffusion models to determine the kinetics of adsorption process. 
Table 3 Langmuir, Freundlich and Temkin isotherms and their constants at different temperatures

\begin{tabular}{|c|c|c|c|c|c|c|c|c|c|c|}
\hline \multirow{2}{*}{$\begin{array}{l}\text { Temperature } \\
\text { Temp (K) }\end{array}$} & \multicolumn{4}{|c|}{ Langmuir constants } & \multicolumn{3}{|c|}{ Freundlich constants } & \multicolumn{3}{|c|}{ Temkin constants } \\
\hline & $q_{m}(\mathrm{mg} / \mathrm{g})$ & $b_{\mathrm{L}}(\mathrm{L} / \mathrm{mg})$ & $R^{2}$ & $R_{L}$ & $n$ & $K_{f}$ & $R^{2}$ & $B$ & $\mathrm{~K}_{\mathrm{T}}$ & $R^{2}$ \\
\hline 308 & 6.711 & 1.886 & 0.996 & 0.01 & 2.40 & 3.715 & 0.960 & 2.962 & 24.871 & 0.998 \\
\hline 313 & 6.757 & 2.145 & 0.992 & 0.009 & 2.43 & 3.971 & 0.980 & 2.916 & 30.683 & 0.990 \\
\hline 318 & 6.757 & 2.552 & 0.985 & 0.007 & 2.53 & 4.236 & 0.994 & 2.763 & 43.531 & 0.972 \\
\hline
\end{tabular}

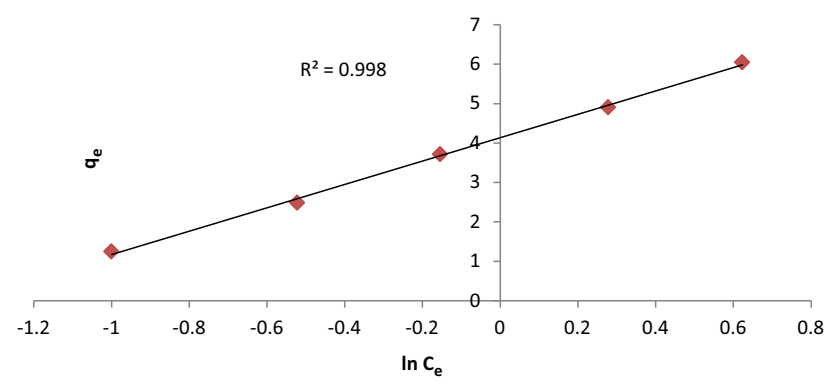

Fig. 12 Temkin adsorption isotherm for Rhodamine B adsorption at $308 \mathrm{~K}$

\section{Pseudo-first order kinetic model}

The data is subjected to Lagergren's first order equation. It has been found that it does not fit to straight line.

\section{Pseudo-second order kinetic model}

The integrated linear form of pseudo-second order kinetic model is given below [57]

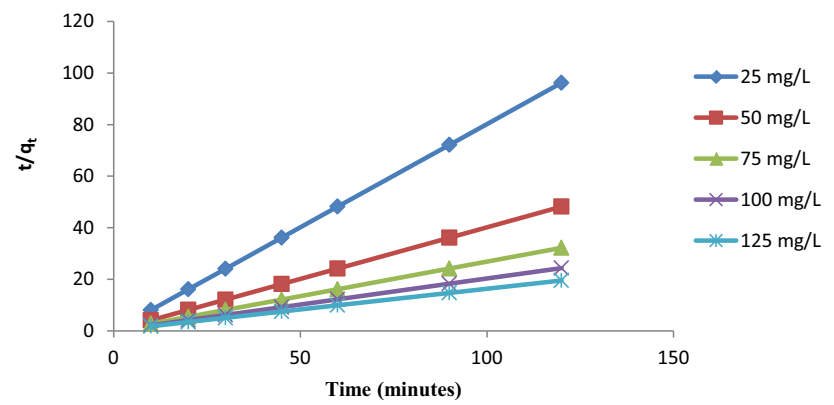

Fig. 13 Pseudo-second order kinetics for Rhodamine B adsorption
$\frac{t}{q_{t}}=\frac{1}{\left(K_{2} q_{e}^{2}\right)}+\frac{1}{q_{e}} t$

where $K_{2}$ is the pseudo-second order rate constant $\left(\mathrm{g} \mathrm{mg}^{-1} \mathrm{~min}^{-1}\right)$. For pseudo-second order kinetic model, the linear plot between $t / q_{t}$ verses $t$ shown in Fig. 13. The values of $K_{2}$ and $R_{2}$ have been calculated from the plot, which are represented in Table 4.

\section{Intra-particle diffusion model}

In adsorption process, the adsorbed species are most probably transported from the bulk of the solution into the solid phase through intra-particle diffusion, which is the rate limiting step. In addition, there is a possibility of the adsorbate to diffuse into the interior pores of the adsorbent. Weber and Morris proposed linear equation for intra-particle diffusion model, which is given in the following form [58]

$q_{t}=K_{\mathrm{ipd}} t^{1 / 2}+C$

where $K_{\text {ipd }}$ is the intra-particle diffusion rate constant $\left(\mathrm{mg} \mathrm{g}^{-1} \mathrm{~min}^{-1}\right)$ and $C$ is the constant $\left(\mathrm{mg} \mathrm{g}^{-1}\right)$. The intraparticle diffusion rate constant $K_{\text {ipd }}$ and $C$ have been calculated from the slope and intercept of the plot between $q_{t}$ verses $t^{1 / 2}$ which are listed in Table 4 (Fig. 14).

\section{Thermodynamic parameters}

Thermodynamic parameters, such as free energy change $(\Delta G)$, enthalpy change $(\Delta H)$ and entropy change $(\Delta S)$ have important role for the determination of spontaneity and heat change of the adsorption process. The free energy
Table 4 Pseudo-second order and intra-particle diffusion values for adsorption of Rhodamine B dye

\begin{tabular}{llllllll}
\hline $\mathrm{C}_{0}\left(\mathrm{mg} \mathrm{L}^{-1}\right)$ & \multicolumn{2}{l}{ Pseudo-second order calculated } & & & \multicolumn{3}{l}{ Intra-particle diffusion parameters } \\
\cline { 2 - 3 } & $K_{2}\left(\mathrm{~g} \mathrm{mg}^{-1} \mathrm{~min}^{-1}\right)$ & $q_{\mathrm{e}}(\mathrm{mg} / \mathrm{g})$ & $R^{2}$ & & $K_{\mathrm{ipd}}\left(\mathrm{mg} \mathrm{g}^{-1} \mathrm{~min}^{-1}\right)$ & $C\left(\mathrm{mg} \mathrm{g}^{-1}\right)$ & $R^{2}$ \\
\hline 25 & 7.1276 & 1.2484 & 1.000 & 0.001 & 1.234 & 0.733 \\
50 & 1.344 & 2.5000 & 1.000 & 0.006 & 2.425 & 0.833 \\
75 & 0.6989 & 3.7453 & 1.000 & 0.015 & 3.582 & 0.677 \\
100 & 0.2992 & 4.9751 & 1.000 & 0.031 & 4.633 & 0.780 \\
125 & 0.1184 & 6.2110 & 1.000 & 0.065 & 5.496 & 0.870 \\
\hline
\end{tabular}




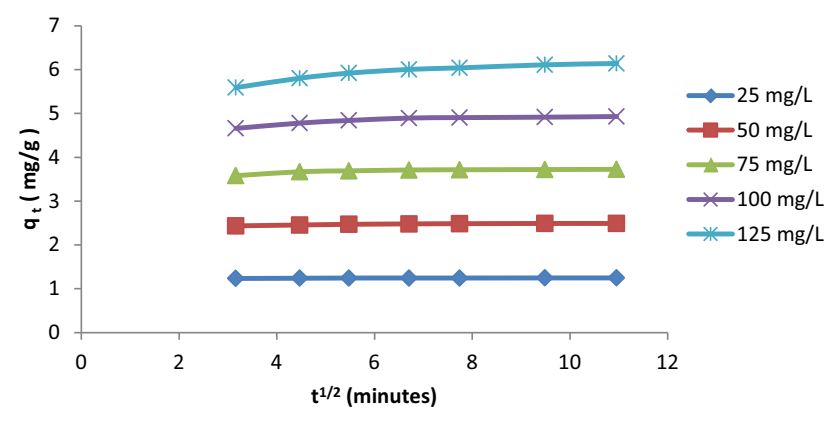

Fig. 14 Intra-particle diffusion kinetics for Rhodamine B adsorption

Table 5 Thermodynamic parameters for adsorption of Rhodamine B dye

\begin{tabular}{lrrrrl}
\hline $\begin{array}{l}C_{o} \\
\left.(\mathrm{mg} \mathrm{L})^{-1}\right)\end{array}$ & \multicolumn{2}{c}{$-\Delta G\left(\mathrm{KJ} \mathrm{mol}^{-1}\right)$} & & $\begin{array}{l}\Delta H \\
\left(\mathrm{KJ} \mathrm{mol}^{-1}\right)\end{array}$ & $\begin{array}{l}\Delta S(\mathrm{KJ} \\
\left.\mathrm{mol}^{-1} \mathrm{~K}^{-1}\right)\end{array}$ \\
\cline { 2 - 5 } & $308 \mathrm{~K}$ & $313 \mathrm{~K}$ & $318 \mathrm{~K}$ & & \\
\hline 25 & 14.1287 & 15.1091 & 16.4252 & 52.12 & 0.2150 \\
50 & 13.0849 & 13.5732 & 13.9947 & 13.88 & 0.0876 \\
75 & 11.9452 & 12.3335 & 12.7442 & 11.70 & 0.0768 \\
100 & 10.2198 & 10.2733 & 11.0634 & 17.83 & 0.0903 \\
125 & 8.6012 & 9.3078 & 9.9829 & 31.46 & 0.1301 \\
\hline
\end{tabular}

change $(\Delta G)$ has been calculated from the thermodynamic equilibrium constant $K_{0}$ using the following equation:

$\Delta G=-R T \ln K_{o}$

where $R$ is the universal gas constant; $T$ is the absolute temperature in Kelvin.

Enthalpy change $\Delta H$ and entropy change $\Delta S$ have been evaluated from the Van't Hoff equation

$\ln K_{o}=\Delta S / R-\Delta H / R T$

$\Delta H$ and $\Delta S$ has been calculated from the slope and intercept of the plot between $\ln K_{o}$ verses $1 / T$. Thermodynamic parameters obtained from the adsorption of Rhodamine B dye onto CMSW are given in Table 5. The negative value of $\Delta G$ confirms the feasibility of adsorption process. The increase of values of $\Delta G$ with temperature indicates that adsorption process is more favourable at higher temperatures, probably as a result of the increased mobility of dye species in solution. The positive values of $\Delta H$ confirm endothermic nature of adsorption process. The lower values of $\Delta S$ indicate that entropy decreases at solid-liquid interface.

\section{Conclusion}

This study investigated the adsorption of a basic dye Rhodamine B onto CMSW as a function of adsorbent dose, initial dye concentration, $\mathrm{pH}$ and temperature. From the results it has been concluded that
1. CMSW is an efficient adsorbent for the removal of Rhodamine B dye in a smaller contact time, i.e., $60 \mathrm{~min}$. Approximately $90 \%$ of dye has been removed within 10 min for each initial concentration.

2. The equilibrium adsorption data has been analysed by Langmuir, Freundlich and Temkin adsorption isotherms. The value of regression coefficient $R^{2}$ indicates that Langmuir, Freundlich and Temkin isotherms well describes the process. The monolayer adsorption capacity is $6.711,6.757$ and $6.757 \mathrm{mg} \mathrm{g}^{-1}$ at 308 , 313 and $318 \mathrm{~K}$ temperature.

3. Kinetic studies showed that data is best described by pseudo-second order kinetics with very good regression coefficient value equal to unity.

4. The negative value of thermodynamic parameters $\Delta G$ indicates the spontaneity, where as positive values of $\Delta H$ confirms the endothermic behaviour of the adsorption process. The low value of enthalpy change shows that it is a case of physio-sorption.

5. Desorption of the dye can be successfully carried out using different solvents. The adsorbent treated with hydrochloric acid show maximum recycling efficiency.

Taking into account the results of this study it has been concluded that CMSW can be considered as promising, eco-friendly adsorbent with low-cost production for the removal of dyes from wastewater in small time.

\section{Compliance with ethical standards}

Conflict of interest The authors declare that they have no competing interests.

Open Access This article is distributed under the terms of the Creative Commons Attribution 4.0 International License (http://creative commons.org/licenses/by/4.0/), which permits unrestricted use, distribution, and reproduction in any medium, provided you give appropriate credit to the original author(s) and the source, provide a link to the Creative Commons license, and indicate if changes were made.

\section{References}

1. Kothari DD (2008) Rupee-value appreciation-calculating the crisis. Mod Text 3(1):26-29

2. Kant R (2012) Textile dyeing industry an environmental hazard. Nat Sci 4:22-26

3. Gonawala KH, Mehta MJ (2014) Removal of colour from different dye wastewater using ferric oxide as an adsorbent. Int $\mathrm{J}$ Eng Res Appl 4(5):102-109

4. Errais E, Duplay J, Darragi F (2010) Textile dye removal by natural clay-case study of Fouchana Tunisian clay. Environ Technol 31:373-380

5. Das SK, Ghosh P, Ghosh I, Guha AK (2008) Adsorption of Rhodamine B on Rhizopus oryzae: role of functional groups and cell wall components. J Colloids Surf B 65:30-34

6. Kaur H, Kaur R (2014) Removal of Rhodamine-B dye from aqueous solution onto Pigeon dropping: adsorption, kinetic, 
equilibrium and thermodynamic studies. J Mater Environ Sci 5(6): $1830-1838$

7. Shen K, Gondal MA (2013) Removal of hazardous Rhodamine B dye from water by adsorption onto exhausted coffee ground. J Saudi Chem Soc. doi:10.1016/j.jscs.2013.11.005

8. Oliveira EGL Jr, Rodrigues JJ, de Olivrira HP (2011) Influence of surfactant on the fast photodegradation of Rhodamine B induced by $\mathrm{TiO}_{2}$ dispersions in aqueous solution. Chem Eng J 172:96-101

9. Ahmad A, Setapar SHM, Chuonq CS, Khatoon A, Wani WA, Kumar A, Rafatullah M (2015) Recent advances in new generation dye removal technologies: novel search for approaches to reprocess wastewater. RSC Adv 5(39):30801-30818

10. Raghu S, Basha CA (2007) Chemical or electrochemical techniques followed by ion exchange, for recycle the textile dye wastewater. J Hazard Mater 149:324-330. doi:10.1016/j.hazmat. 2007.03.087

11. Dragan ES, Dinu IA (2008) Removal of azo dyes from aqueous solution by coagulation/flocculation with strong polycations. Res J Chem Environ 12(3):5-11

12. Asl MK, Bahrami F (2014) Removal of vat dyes from coloured wastewater by reverse osmosis process. Bull Georg Natl Acad Sci 8(1):260-267

13. Wu J, Eiteman M, Law S (1998) Evaluation of membrane filtration and ozonation processes for treatment of reactive-dye wastewater. J Environ Eng 124(3):272-277

14. Babu BR, Parande AK, Kumar SA, Bhanu SU (2011) Treatment of dye effluent by electrochemical and biological processes. Open J Saf Sci Technol 1:12-18

15. Rajkumar K, Muthukumar M, Mangalaraja RV (2015) Electrochemical degradation of C.I. Reactive Orange 107 using Gadolinium $\left(\mathrm{Gd}^{3+}\right)$, Neodymium $\left(\mathrm{Nd}^{3+}\right)$ and Samarium $\left(\mathrm{Sm}^{3+}\right)$ doped cerium oxide nanoparticles. Int J Ind Chem 6:285-295

16. Gupta VK, Jain R, Nayak A, Agarwal S, Shrivastva M (2011) Removal of hazardous dye tartrazine by photodegradation on titanium dioxide surface. Mater Sci Eng C 31(5):1062-1067

17. Karthikeyan S, Gupta VK, Boopthy R, Titus A, Sekaran G (2012) A new approach for the degradation of high concentration of aromatic amine by heterocatalytic Fenton oxidation: kinetic and spectroscopic studies. J Mol Liquids 35:153-163

18. Kaur H, Thakur A (2014) Adsorption of Congo red dye from aqueous solution onto Ash of Cassia Fistula seeds: kinetic and thermodynamic studies. Chem Sci Rev Lett 3(11S):159-169

19. Saleh TA, Gupta VK (2014) Processing methods, characteristics and adsorption behaviour of tire derived carbons: a review. Adv Colloid Interface Sci 211:93-101

20. Hermawan AA, Bing T, Salamatinia B (2015) Application and optimization of using recycled pulp for Methylene Blue removal from wastewater: a response surface methodology approach. Int J Environ Sci Dev 6(4):267-274

21. Suteu D, Malutan T (2013) Industrial cellolignin waste as adsorbent for removal of Methylene blue dye from aqueous solution. Bioresources 8(1):427-446

22. Mittal A, Mittal J, Malviya A, Gupta VK (2010) Removal and recovery of Chrysoidine $\mathrm{Y}$ from aqueous solution by waste material. J Colloid Interface Sci 344:497-507

23. Mathivan M, Saranathan ES (2015) Sugarcane Bagasse-a low cost adsorbent for removal of Methylene Blue from aqueous solution. J Chem Pharm Res 7(1):817-822

24. Jain AK, Gupta VK, Bhatnagara A, Suhas S (2003) A comparative study of adsorbent prepared from industrial waste for removal of dyes. Sep Sci Technol 38(2):463-481

25. Vakili M, Rafatullah M, Salamatinia B, Abdullah AZ, Ibrahim MH, Tan KB, Gholami Z, Amouzgar P (2014) Application of chitosan and its derivatives as adsorbents for dye removal from water and wastewater: a review. Carbohydr Polym 113:115-130
26. Gupta VK, Mittal A, Jhare D, Mitaal J (2012) Batch and bulk removal of hazardous colouring agent Rose Bengal by adsorption technique using Bottom Ash as adsorbent. RCS Adv 2:8381-8389

27. Ahmad T, Danish M, Rafatullah M, Ghazali A, Sulaiman O, Hashim R, Nasir M, Ibrahim M (2012) The use of date palm as a potential adsorbent for wastewater treatment: a review. Environ Sci Pollut Res 19(5):1464-1484

28. Senthilkumar S, Kalaamani P, Subburaam CV (2006) Liquid phase adsorption of crystal violet onto activated carbon derived from male flowers of coconut tree. J Hazard Mater 136(3):800-808

29. Mittal A, Mittal J, Malviya A, Kaur D, Gupta VK (2010) Decoloration treatment of a hazardous triarylmethane dye, Light Green SF (Yellowish) by waste material adsorbents. J Colloid Interface Sci 342:518-527

30. Abdullah R, Ishak CF, Kadir WR, Bakar RA (2015) Characterization and feasibility assessment of recycled paper mill sludge for land application in relation to the environment. Int $\mathrm{J}$ Environ Res Public Health 12:9314-9329

31. Rangabhashiyam S, Selvaraju N (2015) Efficacy of unmodified and chemically modified Swietenia Mahogani shells for the removal of hexavalent chromium from simulated wastewater. J Mol Liquids 209:487-497

32. Shah J, Jan MR, Haq A, Khan Y (2013) Removal of Rhodamine B dye from aqueous solution and wastewater by Walnut shells: kinetic, equilibrium and thermodynamic studies. Front Chem Sci Eng 7(9):428-436

33. Kooh MRR, Dahri MK, Lim LBL (2016) The removal of Rhodamine B dye from aqueous solution using Casuarina equisetifolia needles as adsorbent. Cogent Environ Sci. doi:10.1080/ 23311843.2016.1140553

34. Jain R, Mathur M, Sikarwar S, Mittal A (2007) Removal of hazardous dye Rhodamine $B$ through photocatalytic and adsorption treatments. J Environ Manag 85:956-964

35. Balasubramani K, Sivarajasekar N (2014) Adsorption studies of organic pollutants onto activated carbon. Int J Innov Res Sci Eng Technol 3(3):10575-10581

36. Santhi M, Kumar PE (2015) Adsorption of Rhodamine B from an aqueous solution: kinetic, equilibrium and thermodynamic studies. Int J Innov Res Sci Eng Technol 4:497-510

37. Sumanjit WT, Kansal I (2008) Removal of Rhodamine B by adsorption on walnut shell charcoal. J Surf Sci Technol 24(3-4):179-193

38. Rangabhashiyam S, Nakkeeran E, Anu N, Selvaraju N (2015) Biosorption potentials of a novel ficus auriculata leaves powder for the sequestration hexavalent chromium from aqueous solutions. Res Chem Intermed 41(11):8405-8424

39. Ponnusamy SK, Subramaniam R (2013) Process optimization studies of Congo red dye adsorption onto Cashew nut shell using Response surface methodology. Int J Ind Chem 4(17):2-10

40. Kavitha K, Sentamilselvi MM (2015) Removal of Malachite Green from aqueous solution using low cost adsorbent. Int J Curr Res Acad Rev 3(6):97-104

41. Mittal A, Kaur D, Malviya A, Mittal J, Gupta VK (2009) Adsorption studies on the removal of coloring agent phenol red from wastewater using waste materials as adsorbents. J Colloid Interface Sci 337:345-354

42. Venkatraman BR, Gayathri U, Elavarasi S, Arivoli S (2012) Removal of Rhodamine B dye from aqueous solution using the acid activated Cynodondactylon carbon. Der Chem Sin 3(1):99-113

43. Hema M, Arivoli S (2009) Rhodamine B adsorption by activated carbon: kinetic and equilibrium studies. Ind $\mathrm{J}$ Chem Technol $16: 38-45$ 
44. Mohan D, Singh KP, Singh G, Kumar K (2002) Removal of dyes from wastewater using Flyash, a low cost adsorbent. Ind Eng Chem Res 41:3688-3695

45. Langmuir I (1918) The adsorption of gases on plane surfaces of glass, mica and platinum. J Am Chem Soc 40:13611403

46. Khan TA, Imran A, Singh VV, Sharma S (2009) Utilization of flash as low-cost adsorbent for the removal of Methylene Blue, Malachite Green and Rhodamine B dyes from textile wastewater. J Environ Prot Sci 3:11-22

47. Kannan N, Murugavel S (2007) Column studies on the removal of dyes Rhodamine-B, Congo red and Acid violet by adsorption on various adsorbents. EJEAFChem 6:1860-1868

48. Vasu AE (2008) Studies on the removal of Rhodamine B and Malachite Green from aqueous solution by activated carbon. J Chem 5(4):844-852

49. Namasivayam C, Radhika R, Suba S (2001) Uptake of dyes by a promising locally available agriculture solid waste: coir pith. Waste Manag 21(4):381-387

50. Namasivayam C, Muniasamy N, Gayatri K, Rani M, Ranganathan K (1996) Removal of dyes from aqueous solution by cellulosic waste orange peel. Bioresour Technol 57:37-43
51. Koyuncu M, Kul AR (2014) Thermodynamics and adsorption studies of dye (Rhodamine B) onto natural diatomite. Physicochem Probl Miner Process 50(2):631-643

52. Gurunathan V, Gowthami P (2016) The effective removal of Rhodamine B dye by activated carbon (Mimusops Elengi) by adsorption studies. Int J Res Inst 3(21):575-581

53. Khan TA, Singh VV, Kumar D (2004) Removal of some basic dyes from artificial textile wastewater by adsorption onto Akash Kinari coal. J Sci Ind Res 863:355-364

54. Khan TA, Sharma S, Ali I (2011) Adsorption of Rhodamine B dye from aqueous solution onto acid activated Mango (Magnifera indica) leaf powder: equilibrium, kinetic and thermodynamic studies. J Tozicol Environ Health Sci 3(10):286-297

55. Kareem SH, Al-Hussien EABD (2012) Adsorption of Congo red, Rhodamine B and Disperse blue dyes from aqueous solution onto Raw Flint Clay. Baghdad Sci J 9(4):680-688

56. Freundlich H, Hellen W (1993) The adsorption of cis- and transazobenzene. J Am Chem Soc 61:2-28

57. Ho YS, McKay G (1999) Pseudo-second order model for sorption processes. Process Biochem 34:451-465

58. Weber WH, Morris JC (1963) Kinetics of adsorption on carbon from solution. J Sanit Eng Div Am Soc Civ Eng 89(2):31-60 